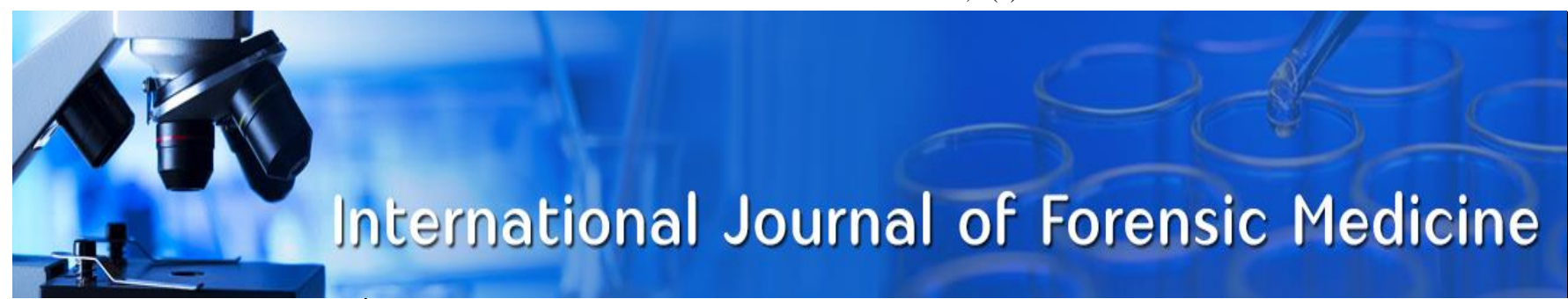

E-ISSN: 2707-4455

P-ISSN: 2707-4447

www.forensicpaper.com/

IJFM 2019; 1(1): 19-21

Received: 15-11-2019

Accepted: 18-12-2019

\section{Dr. Aman Mehra}

Department of Forensic medicine, Pt. Jawahar Lal Nehru Memorial Medical College, Raipur, Chhattisgarh, India

\section{Pattern of head injuries - An autopsy study}

DOI: https://doi.org/10.33545/27074447.2019.v1.i1a.7

\begin{abstract}
Background: India being one of the fastest developing nations in the world with a huge population density, the road traffic density is also increasing. The present study was conducted to assess pattern of head injury in population.

Materials \& Methods: This study was conducted on 140 victims of both genders who died in road traffic accidents and undergoing post-mortem in department of Forensic Medicine. Detailed personal information was recorded from relatives/accompanies of victim.

Results: Out of 140, males were 80 and females were 60 . Pattern of skull fracture was linear vertex fracture seen in $35 \%$, communited in $24 \%$, depressed vertex fracture seen in $10 \%$, basal fracture in $21 \%$ and crush fracture in $10 \%$. The difference was significant $(P<0.05)$. Maximum deaths occurred in $<24$ hours $(32 \%)$ followed by 24 hours -1 week (20\%), 1 week- 2 weeks (15\%), 2 weeks- 4 weeks $(13 \%)$ and 4 weeks- 5 weeks $(10 \%)$. The difference was significant $(P<0.05)$.

Conclusion: Head injuries are most prominent are to be affected in road traffic accidents.
\end{abstract}

Keywords: head, road traffic, fatal

\section{Introduction}

India being one of the fastest developing nations in the world with a huge population density, the road traffic density is also increasing ${ }^{[1]}$. In India, for individuals older than four years of age, more life years are lost due to traffic accidents than cardiovascular diseases. India accounts for about $10 \%$ of road accident fatalities worldwide. Head injury has been defined as "a morbid state, resulting from gross or subtle structural changes in the scalp, skull, and/or the contents of skull, produced by mechanical forces ${ }^{[2]}$. The head being the most vulnerable part of the body is involved frequently and lead to morbidity and mortality in road traffic accidents ${ }^{[3,4]}$.

The magnitude of Road traffic accidents and fatalities in India is alarming. In 2009, it reached to 4.22 lakh road traffic accidents and 1.27 lakh road traffic fatalities ${ }^{[5]}$. The rate of incidence of head injury is higher in India because of its traffic patterns and possibly the lack of preventive measures such as helmets in motor cyclists and seatbelts in automobiles, poorly controlled traffic conditions and road conditions ${ }^{[6]}$.

Depending upon whether or not the dura matter was torn, the head injury may be termed as open or closed type. The extent and degree of injury to the skull and its content is not necessarily proportional to the quantum of force applied to the head. According to Munro, any type of cranio-cerebral injury is possible with any kind of blow on any sort of head ${ }^{[7]}$. The present study was conducted to assess pattern of head injury in population.

\section{Materials \& Methods}

This study was conducted on 140 victims of both genders who died in road traffic accidents and undergoing post-mortem in department of Forensic Medicine. Ethical clearance was obtained prior to the start.

Detailed personal information was recorded from relatives/accompanies of victim. All cases were thoroughly analyzed and subjected to statistical analysis. $\mathrm{P}$ value of $<0.05$ was considered as significant.
Corresponding Author: Dr. Aman Mehra Department of Forensic medicine, Pt. Jawahar Lal Nehru Memorial Medical College, Raipur, Chhattisgarh, India 


\section{Results}

Table I: Distribution of victims

\begin{tabular}{|c|c|c|}
\hline Gender & Males & Females \\
\hline Number & 80 & 60 \\
\hline
\end{tabular}

Table I, graph I shows that out of 140, males were 80 and females were 60 .

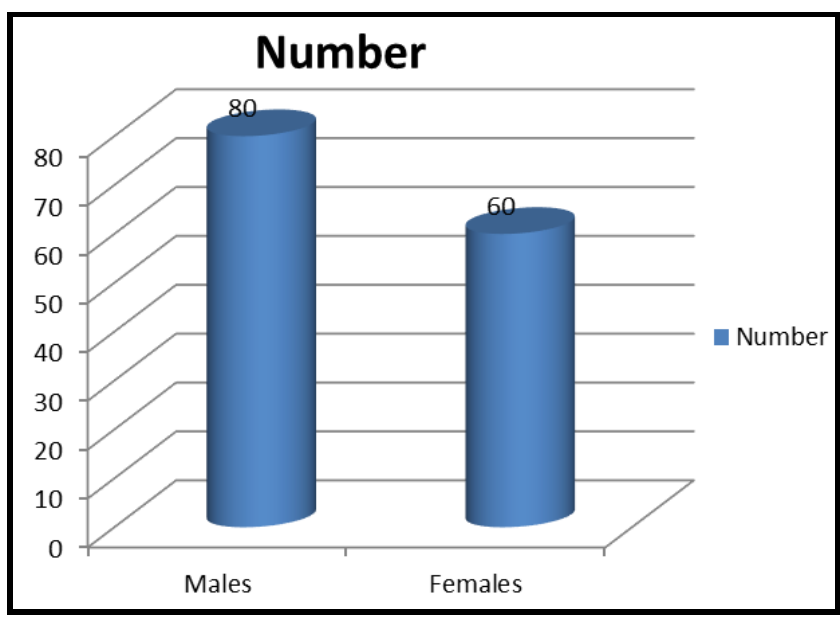

Graph I: Distribution of victims

Table II: Pattern of skull fracture

\begin{tabular}{|c|c|c|}
\hline Pattern & Percentage & \multirow{2}{*}{ P value } \\
\hline Linear vertex & $35 \%$ & \multirow{2}{*}{0.05} \\
\hline Communited & $24 \%$ & \\
\hline Depressed & $10 \%$ & \\
\hline Basal & $21 \%$ & \\
\hline Crush & $10 \%$ & \\
\hline
\end{tabular}

Table II, graph II shows that pattern of skull fracture was linear vertex fracture seen in $35 \%$, communited in $24 \%$, depressed vertex fracture seen in $10 \%$, basal fracture in $21 \%$ and crush fracture in $10 \%$. The difference was significant $(P<0.05)$.

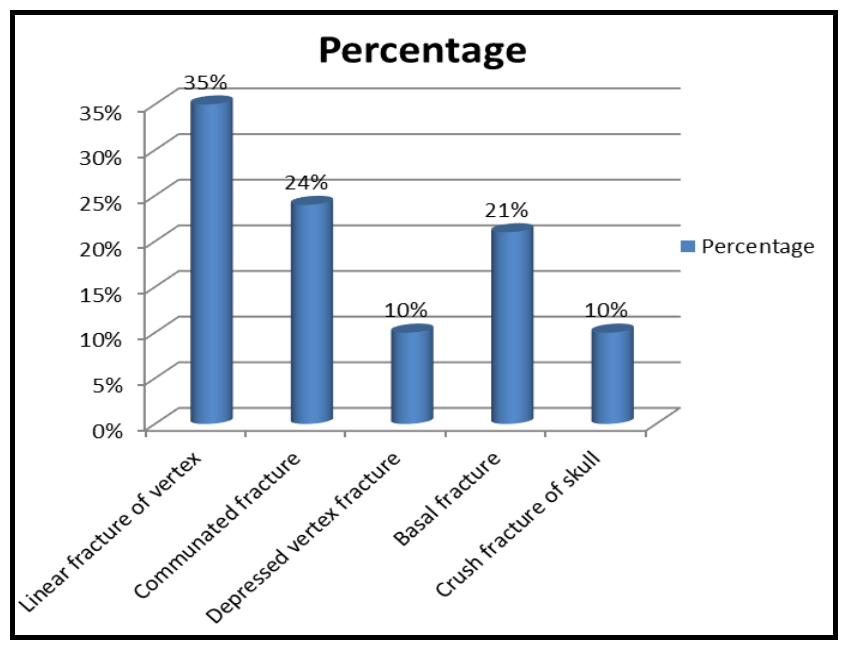

Graph II: Pattern of skull fracture

Table III: Survival period of victims

\begin{tabular}{|c|c|c|}
\hline Survival period & Percentage & P value \\
\hline$<24$ hours & $32 \%$ & \multirow{2}{*}{0.01} \\
\hline 24 hrs- 1 week & $20 \%$ & \\
\hline 1 week- 2 weeks & $15 \%$ & \\
\hline 2 weeks- 4 weeks & $13 \%$ & \\
\hline 4 weeks- 5 weeks & $10 \%$ & \\
\hline
\end{tabular}

Table III, graph III shows that maximum deaths occurred in $<24$ hours $(32 \%)$ followed by 24 hours -1 week $(20 \%), 1$ week- 2 weeks (15\%), 2 weeks- 4 weeks $(13 \%)$ and 4 weeks- 5 weeks $(10 \%)$. The difference was significant $(P<$ $0.05)$.

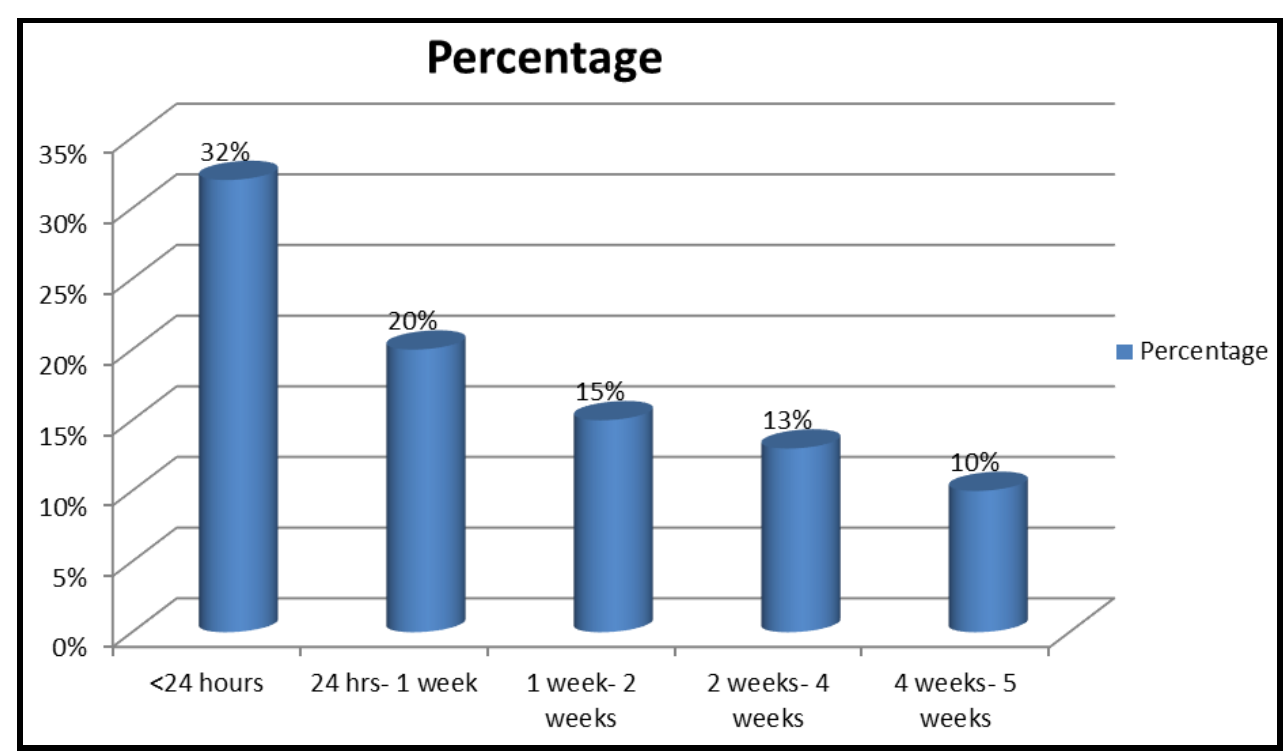

Graph III: Survival period of victims

\section{Discussion}

WHO defined the accident as, "an unexpected, unplanned occurrence that may involve injury." Head injuries are responsible for more than one-fourth of all traumatic deaths and nearly two-third of road traffic accident. In medicolegal practice blunt head trauma are most frequently caused by traffic accident, fall from height, assault, train accident etc ${ }^{[8]}$. The present study was conducted to assess pattern of head injury in population.

In present study, out of 140 , males were 80 and females were 60 . Hanumantha et al. ${ }^{\left[{ }^{9]}\right.}$ in their study undertaken on 138 victims of road traffic accidents, died due to head injury to find out the patterns of head injuries, their age and sex distribution and site distribution of different types of 
fractures. The highest incidence was seen in age group of 21-30 years and males clearly outnumbered females. In the present study, most of the incidents occurred between 1200 to 1800 hours. The maximum number of victims $(39.57 \%)$ died while on the way to hospital. The motor-cyclists were the commonest group of victims and trucks being the commonest offending vehicles. Intracranial hemorrhages were seen in 113 cases, skull fractures were found in 95 cases and injury to brain in 51 cases.

We found that pattern of skull fracture was linear vertex fracture seen in $35 \%$, communited in $24 \%$, depressed vertex fracture seen in $10 \%$, basal fracture in $21 \%$ and crush fracture in $10 \%$.

Maximum deaths occurred in $<24$ hours $(32 \%)$ followed by 24 hours - 1 week (20\%), 1 week- 2 weeks (15\%), 2 weeks4 weeks $(13 \%)$ and 4 weeks- 5 weeks $(10 \%)$. The difference was significant $(P<0.05)$.

Incidences are more common among the two wheeler vehicles. Head was the most common site to be injured in RTAs. As motorized two wheeler vehicles constitute a large portion of the vehicle fleet in India, the exponentially increasing number of automobile vehicles, poor adherence to traffic rules and regulations such as maintaining lane discipline, driving in zigzag patterns by public, poorly maintained and congested roads, abuse of alcohol, and lack of awareness about helmets and new generation of high speed vehicles are altogether responsible for accidents ${ }^{[10]}$.

Rajesh et al. ${ }^{[11]}$ found that $36 \%$ died within 24 hours after the accident. $33 \%$ victims survived beyond 24 hours but died within one week. The number of cases decreased with increase in survival period. Only $4 \%$ victims survived for more than 4 weeks. The victim who survived for shortest period of 1 hour had fracture of skull, clavicle, patella and leg bones. The victim who survived for maximum period i.e. 34 days after the accident died due septicemia (intestinal perforation).

Salgado et al. ${ }^{[12]}$ found that twenty-five of 303 (8.3\%) patients reached center within $1 \mathrm{~h}$ (golden hour) of trauma. A majority of patients numbering 159 (52.5\%) reached center within 2-6 h after injury. Of the 303 fatal head injuries, $153(50.5 \%)$ died within $24 \mathrm{~h}$ of reaching center. Ninety-five died within first 12 hours. Ninety-two of the remaining (30.4\%) died 2-7 days after reaching to hospital.

\section{Conclusion}

Head injuries are most prominent are to be affected in road traffic accidents.

\section{References}

1. Bharathy, Kumar S, Singh RKP. Pattern of craniocerebral injuries in fatal vehicular accidents in Patna (Bihar). J Indian Acad Forensic Med. 2014; 36(2):125-9.

2. Honnungar RS, Aramani SC, Vijay Kumar AG, Ajay Kumar TS, Jirli PS. An epidemiological survey of fatal road traffic accidents and their relationship with head injuries. J Indian Acad Forensic Med. 2011; 33(2):41-3.

3. Saleem, Anand Menon, Nagesh KR. Pattern of fatal head injuries due to vehicular accidents in Manipal. JIAFM. 2005; 27(1):19-22.

4. Hanumantha, Narapureddy B, Madithati P. Pattern of craniofacial injuries and Socio demographic distribution of road traffic accidents in Bangalore:
Autopsy study. Int J Med Sci Public Health. 2012; 1:152-156.

5. Singh SK. Road Traffic Accidents in India: Issues and Challenges. Transportation Research Procedia. 2017; 25:4712-23.

6. Sharma A, Harish D. Head injury: The principal killer in road traffic accidents. JIAFM. 2006; 28(4):0971-3.

7. Jha, Pathak A, Desania NL, Verma R. Profile of road traffic accidents \& head injury in Jaipur (Rajasthan). J Indian Acad Forensic Med. 2008; 30(1):6-9.

8. Farooqui, Menon A, Pai VK, Rajeev A. Pattern of fatal head injuries due to vehicular accidents in Mangalore. J Forensic Leg Med. 2008; 15(2):75-7.

9. Hanumantha, Tandle RM, Keoliya AN. Patterns of head injuries in fatal road traffic accidents in a rural district of Maharashtra- Autopsy based study. J Indian Acad Forensic Med. 2011; 33(3):228-31.

10. Singh A, Bhardwaj A, Pathak R, Ahluwalia SK. An epidemiological study of road traffic accident cases at a tertiary care hospital in rural Haryana. Indian Journal of Community Health. 2012; 23(2):53-5.

11. Rajesh, Kaur Balbir, Singh A, Venkteshan M, OP Aggarwal, Singh H. Pattern of injuries due to fatal road traffic accidents in Rural Haryana: An Epidemiological Survey. J Indian Acad Forensic Med. 2012; 34(3):22932.

12. Salgado MSL, Colombage SM. Analysis of fatalities in road accidents. Forensic Sci. Int. 1998; 36:91-6. 